\title{
The Effects of Milling Strategies on Forces, Material Removal Rate, Tool Deflection, and Surface Errors for the Rough Machining of Complex Surfaces
}

\author{
Eyup Bagci* - Ercüment U. Yüncüoğlu \\ Naval Architecture and Maritime Faculty, Y1ldız Technical University, Turkey
}

The high-performance machining of curved surfaces is a highly critical process that is crucial in modern engineering applications. Different methodologies and CAM tools have been developed by manufacturers to improve the efficiency of the sculptured surface milling. The determination of appropriate tool path strategies and milling conditions is crucial in ensuring a high productivity rate, meeting the better surface texture values, and lower cutting forces, tool deflection, and surface errors. The objective of this research is to analyse the effect of tool path strategies on dynamic tool deflection, cutting forces, machining time, effective cutter diameter (ECD), cutter/workpiece engagement (CWE) area, instantaneous material removal rate (IMRR), and machining errors in rough machining of a sculptured surface. The B-rep solid modeling-based simulation and the optimization system were developed and integrated with the commercial CAD/CAM software for 3-axis ball-end milling. The experimental results clearly show the influence of the cutter path strategies on machining times and their importance for reducing time needed and, consequently, costs. It was observed that the profiles of deflection, IMRR values, cutting forces, machining errors and ECD values match very well for cutting strategies. Machining strategies employed include various degrees of zig-zag, profiling, and spiral. The conclusion is that the $90^{\circ}$ zig-zag strategy provokes the lowest cutting forces, tool deflection, and surface error values. The in-house NC simulation system performed well in determining values and the location of milling form errors on the surface.

Keywords: milling, free-form surfaces, MRR, machining errors, cutting strategies

Highlights

- $\quad$ The data presented in this work have shown that the use of different milling strategies when rough ball end milling of free-form surfaces has a significant effect on the on-tool deflection, cutting forces, instantaneous material removal rate, machining time and surface errors

- $\quad$ B-Rep based simulation/optimization system was developed and integrated with CAM software to calculate the effective cutter diameter, cutter/workpiece engagement area, instantaneous material removal rate, and milling errors.

- The $90^{\circ}$ zig-zag cutter path appears to provide preferred results in terms of tool deflection, surface errors, and lower cutting forces. Tool deflection and cutting forces have quantitative and qualitative influence on machining surface errors.

- $\quad$ The proposed B-rep simulation approach is experimentally verified to predict the machining errors.

\section{INTRODUCTION}

Sculptured/curved surfaces, today, are widely used in several industries, for instance, automotive, aerospace, bio-medical components, precision machine design and die-mould industries. Recent improvements in CAM software have allowed the manufacturing of complex curved geometries. The ball-end/nose milling is a flexible process that is capable of milling both convex and concave part surfaces with rough, semi-rough and finish processes. The sculptured surface milling is mostly realized by the repeated motion of a rotating cutter along predefined trajectories. Manufacturing engineers can choose the cutter paths generation approach from a set of typical paths (zig, zig-zag, concentric, radial tool paths, etc.) in commercial CAM software. In addition, these strategies cannot be optimized for all complex surfaces to be milled. A substantial number of studies have examined this subject, and many path-generation approaches have been developed, as shown in Fig. 1 [1] and [2].

The strategies can be sorted into three basic categories: offset, single direction, and raster. In offset milling, the cutter starts at the periphery of the face and then proceeds spirally inwards. In a raster milling strategy (zig, zig-zag, or sweep) the cutting tool moves back and forth across the milled workpiece [3]. In spiral milling, the cutter returns to the start-point of each cycle and then cuts outwards to the next outer cycle. When using a spiral strategy, the cutting time is hugely decreased. The selection of the proper milling strategy in the process of milling will decrease cutting time, improve the surface quality of the finished part and tool life and reduce machining costs and cutting forces. Kurt and Bagci [4] and Lasemi et al. [5] reviewed the recent research literature on milling of complex-curved surfaces and feed-rate optimization approaches. Chen et al. proposed a real-time monitoring system with error compensation to 


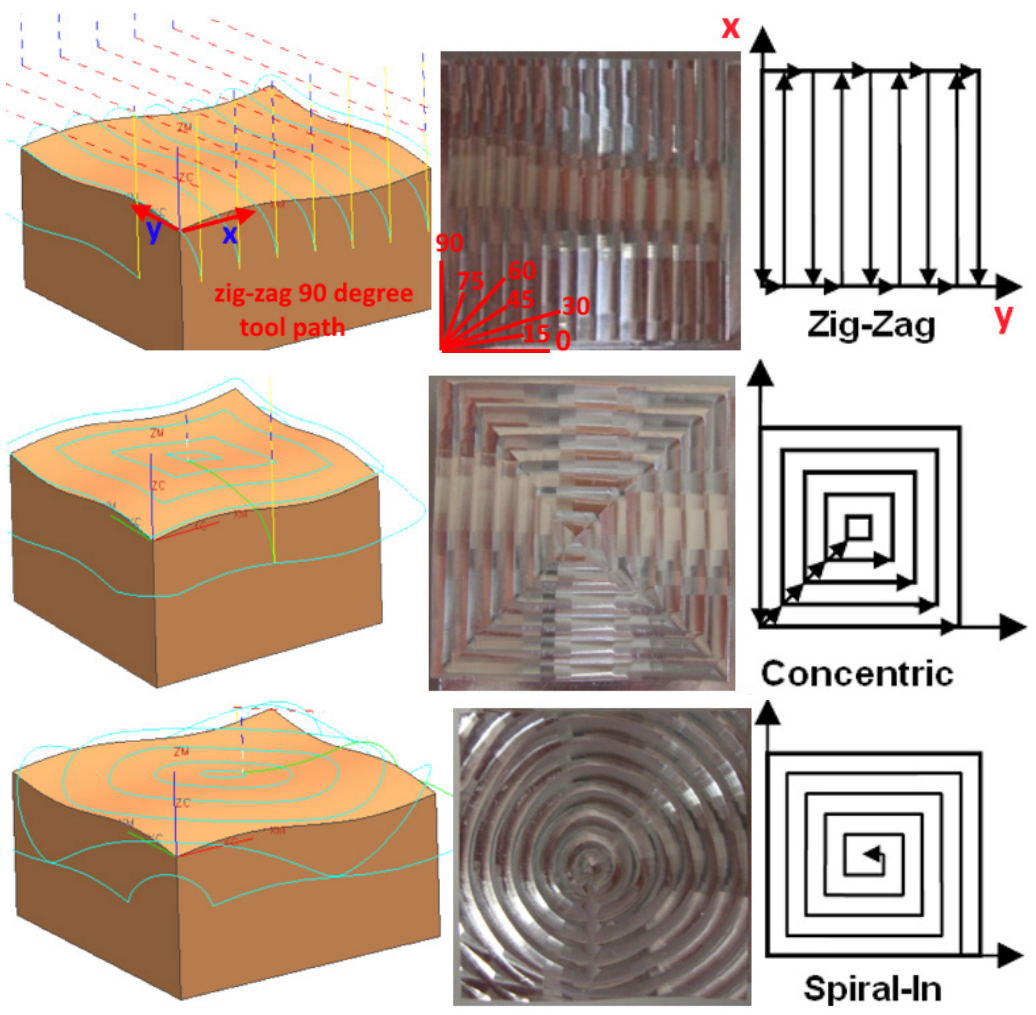

Fig. 1. Representation of cutting patterns and tool-path strategies

enhance dimensional accuracy in the production of complex components. They created a method for the combination of the on-line inspection and the compensation of the machining errors and verified the method by experiments. [6]. Habibi et al. modelled the machining process for force/deflection calculations in a 3D simulation environment. They found that the accuracy of machined features can be improved by about 8 to 10 times a single pass by using a new method [7]. Desai and Rao determined the effect of variable curvature geometries by machining from both parametric directions and using cutters of different diameters. They determined that a considerable amount of shift in the location of peak cutting forces with the change in cutting direction and cutter diameter, particularly in concave regions of the workpiece geometry [8]. Alberti et al. [9] compared the dimensional part errors with cutting time in the milling of Al alloy. They suggested that the tool holder has considerable influence over dimensional accuracy and that type of interpolation appreciably affects the cycle time. Erdim et al. published a method to adjust the feed-rate according to milling force in order to reduce machining time. They concluded that a forcedbased feed-rate scheduling technique gives controllable force magnitudes and surface errors [10].
Kaymakci and Lazoglu proposed a new model to predict the cutting forces, free-form surface topographies, error distributions and cycle times for various tool paths with the integrated milling software [11]. Brooks et al. experimentally investigated the surface metrology of a 12.70 -mm-thick curved plate platform of AISI SS304 material during milling on a vertical three-axis milling machine with three different tool path strategies: ramp, contour, and peripheral. Cutting mechanics and cutting forces were analysed for the defined values of the strategies [12]. Gok et al. focused on investigating optimum cutting parameter values in ball end milling of tool steel with three coated cutters. The effects of tool path styles in the ball end milling of inclined surfaces have been determined. They found that $\mathrm{TiC}$ coating for cutting forces was the most rapidly deteriorating one [13]. Shajari et al. investigated different machining strategies in 3-axis milling of a typical curved geometry part and also developed an approach to the mathematical model to measure the scallop height size and distribution. They determined the optimized strategy based on the results [14]. Vila et al. examined the power consumption of different cutting strategies in face milling operations in order to evaluate the efficiency of each cutting strategy. They found that the 
optimal cutting strategy to ensure a predefined quality specification [15]. Shajari et al. developed a cutting force as a new decision criterion for the best selection of tool paths on convex surfaces. They concluded that the radial strategy provokes the best surface texture and the lowest cutting forces and the spiral strategy signifies the worst surface texture and the highest cutting forces [16]. Izol et al. studied comparison and evaluation of the milling strategies to produce components with freeform surfaces. They suggested a guideline for the production process of tools with sculptured surfaces, such as tools for metal sheet forming, dies, moulds for plastics and many others [17]. Matras et al. presented the analysis results of machining accuracy after the free-form surface milling simulations for different machining strategies. They suggested a guideline of the usage CAD/CAM software in order to measure the machining accuracy for the selected strategies and cutting data [18]. Hassanpour et al. investigated the effect of raster, 3D-offset, spiral and radial tool path strategies and machining parameters on microhardness of a typical curved surface (convex) of stainless steel 1.4903 . They found that the spiral strategy provided the maximum hardness and the radial strategy the minimum hardness [19]. Pahole et al. studied the influence of the $\mathrm{CNC}$ machining direction during high-speed milling on the durability of the engraving within the forging tool. They found that the correct milling strategy can often cause an increase in the durability of a forging tool by about one third [20]. Schützer et al. developed a method to use free-form features to improve the automatic generation of highspeed machining information for specific geometric areas to create HSC free-form manufacturing features. Their approach reduces significantly the programming time to produce HSC appropriate tool paths for the same quality [21]. Lazoglu et al. developed an approach to generate optimized tool paths for freeform surfaces. They claim that their approach is the first method for generating the tool paths based on process mechanics for globally minimizing the cutting forces for any given free-form surface [22]. Zang et al. examined 3D tool paths' effects on the CNC efficiency, surface quality and form accuracy. It is found that the parallel tool path, which is one of the 3D tool path strategies with a 2-axes driving mode, can improve the surface quality and form accuracy in the actual milling of a complex freeform surface [23]. Wei et al. studied an integrated form error compensation approach for ball-end milling of sculptured surface with a z-level contouring tool path and presented the approach reduce form error in ball-end milling of the sculptured surface according to experimental results [24]. Cao et al. examined the curvature radius effect on machining productivity and found that curvature radius has an obvious effect on machining productivity and quality by using experiments [25]. Tan et al. examined the influence of cutter path orientation and the cutting forces, tool life, tool wear, and surface integrity for finish milling of TC17 alloy; they suggested that the horizontal downward orientation produced the highest cutting forces, and vertical downward orientation provided the best tool life, with cut lengths $90 \%$ to $380 \%$ longer than for all other orientations [26]. Uhlmann et al. examined the error sources of freeform surface milling processes, for the decisive factors that significantly influence the productivity and the workpiece quality. They concluded that each error sources proportion may be related to the deviations measured in particular regions of the machined surface [27]. Scandiffio et al. focused an investigation of free-form milling of hard material AISI D6 tool steel using a ball-end cemented carbide cutting tool and created a guideline for cutting tools life [28]. The simulation of the process of NC milling is of main importance in CAM systems. The virtual simulation of machining processes has started to become more important in order to minimize the dissimilarities between the designed and real milled surfaces, and one of the critical technologies for advancing the efficiency and quality of the cutting process is to design and produce. Various approaches to NC milling simulation have been described in the literature, and they can be categorized into three major approaches: solid modeling, spatial partitioning, and discrete vectors. In NC milling, as the cutter moves along the tool trajectories, it forms a swept volume, and a portion of the workpiece is removed. During the tool motion, it is in contact with the workpiece over an instantaneous common surface which is called cutter workpiece engagement (CWE) area. It is required to have an accurate geometric representation of the engagement surface in order to calculate cutting forces, energy consumption, power, cutter deflections, surface quality (texture and errors), and chatter.

Tunc and Stoddart focused evaluating and selecting tool path patterns, offered by the existing CAM packages, for increased chatter-free MRR and the proposed approach. They performed simulations and experiments to show applications of approach [29]. Scandiffio et al. studied the influence of effective cutting speed and tool-surface contact on tool wear and surface roughness. Contrary of other studies, they found that contact between the centre of the tool tip and the workpiece can increase tool life and 
reduce roughness when milling free-form surfaces in hardened steel [30]. Cao et al. proposed a cutting force model considering influence of radius of curvature. They compared analytically estimated cutting forces and actual cutting forces obtained through experiments [31]. Miao et al. studied an efficient solid-based geometric NC simulation approach and performed consecutive Boolean subtractions to simulate the cutting process. Then, they validated simulation by experiment [32]. Li et al. developed a three-axis milling process simulation system based on quadtree-array representation and used to evaluate the performance of the presented method. Their method improved the simulation efficiency significantly [33]. Aras et al. focused a solid modellingbased methodology for finding cutter-workpiece engagements (CWE) generated in five-axis milling of free-form surfaces. They plotted the CWE boundaries from Euclidean 3D space to a parametric space defined by the engagement angle and the depth-of-cut for a given tool geometry [34]. Lee and Nestler presented a methodology to generate a virtual workpiece (VWP). They validated the VWP model by material removal processes, milling and micro-EDM operations [35]. Boz et al. studied two different methods of obtaining CWE maps for three- and five-axis flat and ball-end milling. They verified the methods experimentally and computationally [36].

This paper presents a B-rep solid modelingbased NC simulation and optimization system, which is integrated with the commercial CAM software due to calculation of THE instantaneous material removal rate (IMRR), effective cutter diameter, cutter/ workpiece engagement area (CWE), and machining errors. In this system, simulation of the cutting process is based on solid models of a workpiece, its blank, and a cutter created with modeling functions of a commercial CAD/CAM system and cutting paths generated by the CAM application of the same system. The main objective of this work is to analyse the influence of tool path strategies on dynamic tool deflection, cutting forces, instantaneous material removal rate, effective cutter diameter, machining time and surface errors have been analysed by experimentally and computationally for 3 -axis ballend milling.

\section{EXPERIMENTAL WORKS}

\subsection{Cutting Tools and Workpiece Materials}

The cutting tools used were chosen from the Sandvik Coromat Catalog to machine Aluminium 7075-T651. The chemical composition and mechanical properties of the Al 7075-T6 material are given in Table 1. Cutting tools of $12 \mathrm{~mm}$ diameter, with two teeth, were employed for milling the experimental surfaces. Details of the tools are given in Fig. 2 and Table 2. The cutters were held in a BT-40 taper tool holder. In this work, tool wear was not considered as a criterion affecting the result of the cutting process since the material being utilized is soft.

The experiments were conducted using a $\mathrm{CNC}$ Johnford VMC Model three-axis CNC milling machine equipped with a maximum spindle speed of $12,000 \mathrm{rpm}$ and a $10-\mathrm{kW}$ drive motor, as shown in Fig. 3. This machine was designed to make 3 -axis linear and circular interpolations via ISO format programs in metric and imperial units. Its control unit was a FANUC series O-M. The experiments used rectangular samples $(100 \mathrm{~mm} \times 53 \mathrm{~mm} \times 30$ $\mathrm{mm}$ ) of Al 7075-T651 aerospace alloy. The machined surface is shown in Fig. 4. Several program packages were used in the evaluation of the data and in the experimental design of the study. The specimen was designed in CATIA V5 R17. The same software was also employed, on a personal computer containing an Intel Pentium IV chip and operating at $2.80 \mathrm{GHz}$, for the creation of the CNC part-manufacturing programs used in the study.

Table 1. Chemical composition and mechanical properties of material

\begin{tabular}{|c|c|c|c|c|c|c|c|c|}
\hline \multirow{6}{*}{$\begin{array}{l}\text { Chemical } \\
\text { composition } \\
\text { [wt\%] }\end{array}$} & $\mathrm{Si}$ & $\mathrm{Fe}$ & $\mathrm{Cu}$ & $\mathrm{Mn}$ & $\mathrm{Mg}$ & $\mathrm{Cr}$ & $\mathrm{Ag}$ & $B$ \\
\hline & 0.393 & 0.260 & 1.26 & 0.044 & 1.94 & 0.288 & 0.0067 & 0.005 \\
\hline & $\mathrm{Be}$ & $\mathrm{Bi}$ & $\mathrm{Ca}$ & Co & $\mathrm{Ni}$ & $\mathrm{Zn}$ & $\mathrm{Ti}$ & Sn \\
\hline & 0.0028 & 0.001 & 0.048 & 0.032 & 0.027 & 5.92 & 0.086 & 0.0035 \\
\hline & V & $\mathrm{Al}$ & $\mathrm{Li}$ & $\mathrm{Na}$ & $\mathrm{Pb}$ & $\mathrm{Sr}$ & $\mathrm{Zr}$ & $\mathrm{Cd}$ \\
\hline & 0.0087 & 89 & 0.347 & 0.015 & 0.0058 & 0.211 & 0.0014 & 0.0001 \\
\hline \multirow{2}{*}{$\begin{array}{l}\text { Mechanical } \\
\text { properties }\end{array}$} & \multicolumn{2}{|c|}{ Tensile strength [MPa] } & Yield strength [MPa] & \multicolumn{2}{|c|}{ Elongation [\%] } & Shear modulus [MPa] & Tens & dulus [GPa] \\
\hline & \multicolumn{2}{|c|}{503} & 434 & \multicolumn{2}{|c|}{13} & 303 & \multicolumn{2}{|c|}{72} \\
\hline
\end{tabular}


Table 2. The dimensional properties of the tool

\begin{tabular}{lc}
\hline Tool Diameter & $12 \mathrm{~mm}$ \\
\hline Flute & 2 flutes \\
\hline Tool Length & $120 \mathrm{~mm}$ \\
\hline Helix Angle & $30^{\circ}$ \\
\hline Shank Type & Cylindrical \\
\hline
\end{tabular}

Table 3. Cutter path strategies for machining

\begin{tabular}{lcc}
\hline & Tool path strategies & Test \\
\cline { 2 - 3 } & $0^{\circ}$ & 1 \\
\cline { 2 - 3 } & $15^{\circ}$ & 2 \\
\cline { 2 - 3 } & $30^{\circ}$ & 3 \\
\cline { 2 - 3 } & $45^{\circ}$ & 4 \\
\cline { 2 - 3 } & $60^{\circ}$ & 5 \\
\cline { 2 - 3 } Concentric/ & $75^{\circ}$ & 6 \\
\hline contour parallel & $90^{\circ}$ & 7 \\
\cline { 2 - 3 } & $\begin{array}{c}\text { on Part surface- B1 } \\
\text { Step over- constant 3D }\end{array}$ & 8 \\
\hline Spiral & $\begin{array}{c}\text { on Plane- B2 } \\
\text { Step over- constant 2D }\end{array}$ & 9 \\
\hline
\end{tabular}

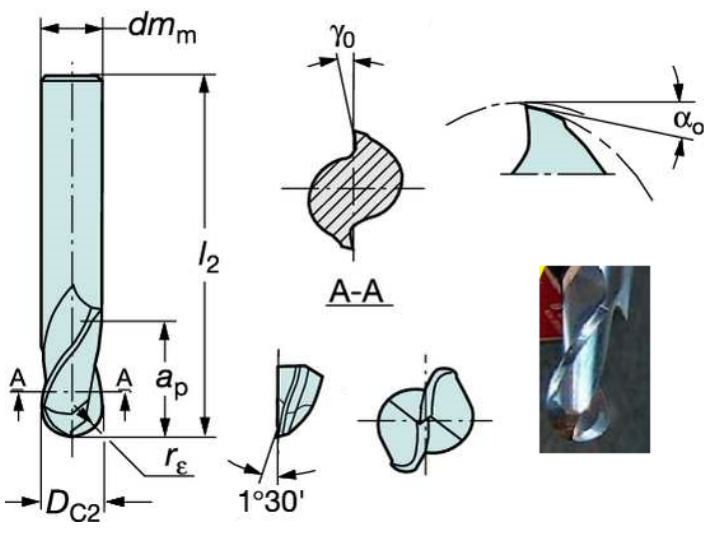

Fig. 2. The ball end milling tool

\subsection{Cutting Conditions}

Three tool path patterns are applied to free-form surface in Fig. 1 and Table 3. Besides these three alternatives, the zig-zag type is used together with six different cut angles. The cut angle is measured

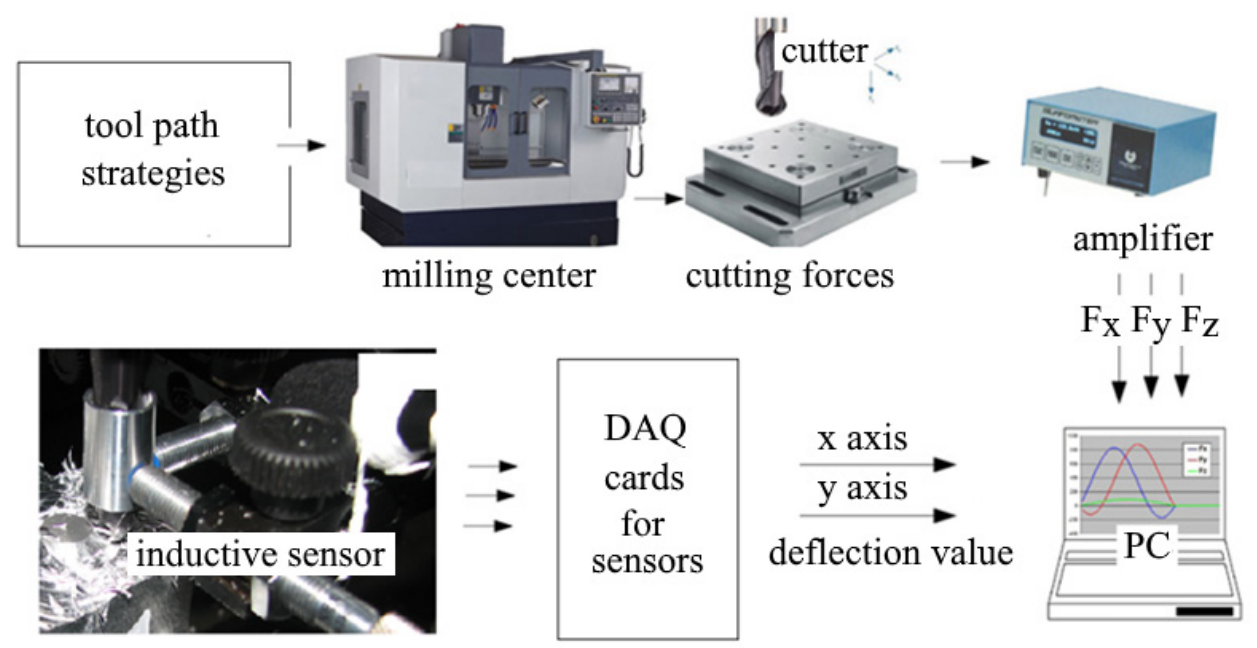

Fig. 3. Experimental setup for measurement of forces and deflection

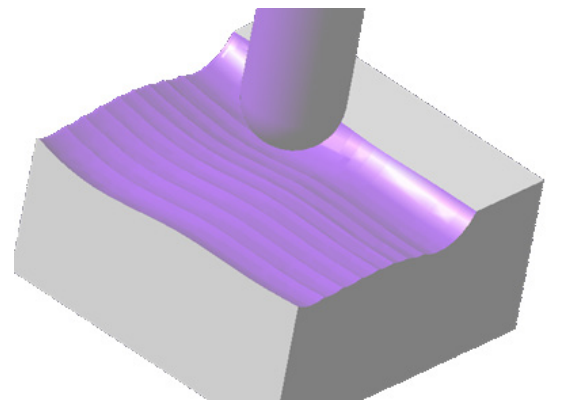

Fig. 4. $C A D$ geometry of used in the experiments with respect to the $\mathrm{X}$ axis in the $\mathrm{X}-\mathrm{Y}$ plane of the coordinate axis. The angle is projected to the floor plane. Tool-path strategies were compared in terms of cutting force, deflection, IMRR, dimensional error values and milling time. The machining parameters are summarized in Table 3. Constant pick feed of 3 $\mathrm{mm}$ was used for all cases. In cutting tests, spindle speed, feedrate and feed per tooth were $600 \mathrm{rpm}$, $96 \mathrm{~mm} / \mathrm{min}$ and $0.08 \mathrm{~mm}$, respectively. The cutter is parallel to the $\mathrm{Z}$ axis, and the maximum and minimum 


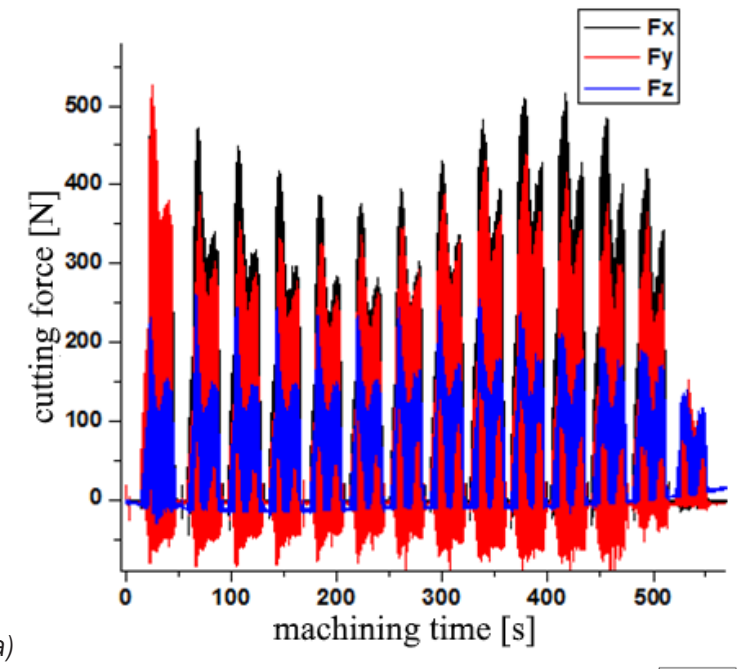

a)
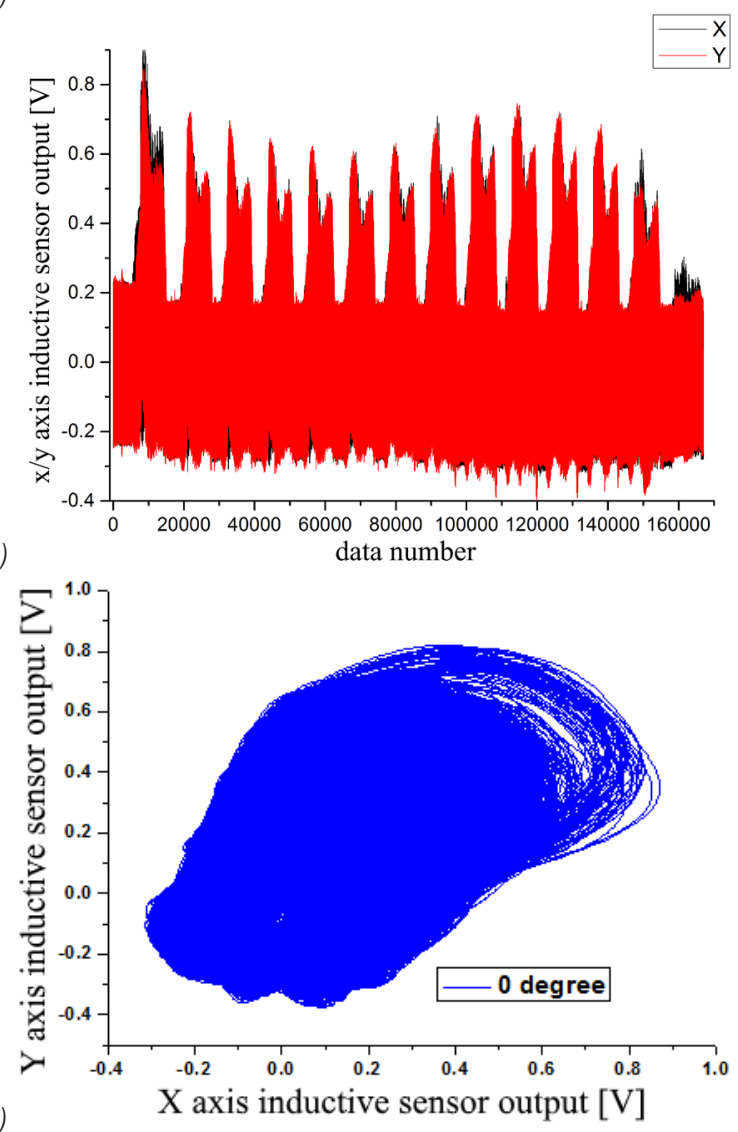

Fig. 5. a) Cutting forces and b), c) the tool deflection for $0^{\circ}$ zig-zag tool path

depths are $5.5 \mathrm{~mm}$ and $1.5 \mathrm{~mm}$ respectively for this part. The machined workpieces can also be seen with the tool path alternatives in Figs. 1 and 8.

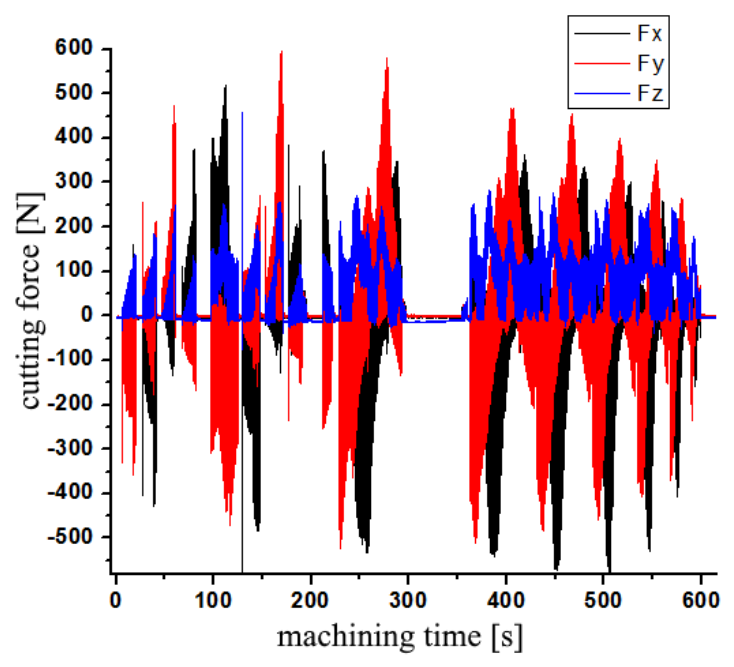

a)
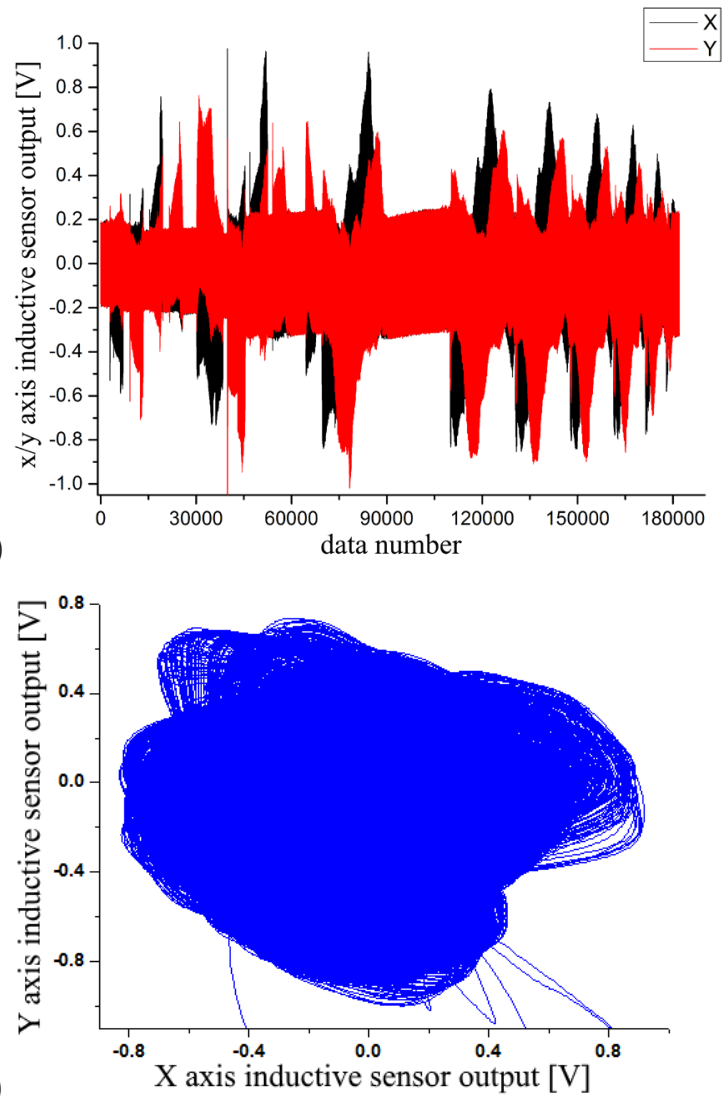

Fig. 6. a) Cutting forces and b), c) the tool deflection for spiral tool path

\subsection{Cutting Forces and Tool Deflection Measurements}

Cutting force measurements $\left(F_{x}, F_{y}\right.$, and $\left.F_{z}\right)$ are made using a Kistler 3-component piezoelectric type 9257A platform dynamometer. The whole system was checked and calibrated prior to use. The cutting 
force data is downloaded from oscilloscope, and information on cutting force signatures is stored onto a PC; after processing of the cutting force data, an analysis is performed using the software as shown in Figs. 5a and 6a.

Cutter deflection measurement has been carried out using two precision inductive displacement sensors placed at $90^{\circ}$ one from the other as shown in Fig. 7. For cutter deflection measurement, an aluminium ring was fitted to the flute part of the cutter and machined after being clamped in the spindle. Figs. $5 \mathrm{~b}$ and $\mathrm{c}$ and $6 \mathrm{~b}$ and $\mathrm{c}$ show the experimental results for cutter deflection measurement for spiral and $0^{\circ}$ zig-zag machining strategies. Tool deflection and cutting forces values showed similar tendencies.

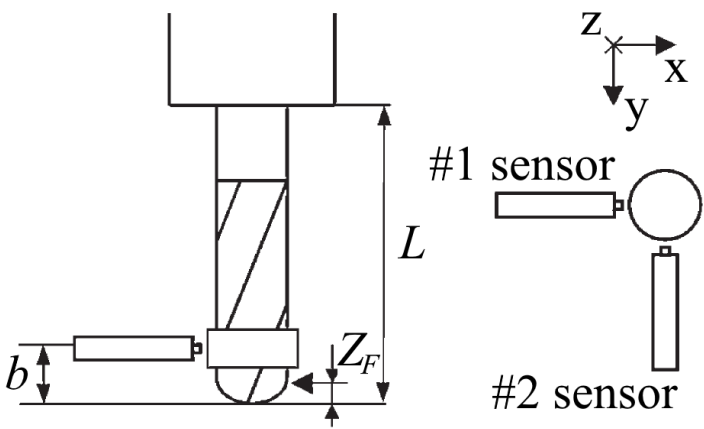

Fig. 7. Tool deflection measurement setup

\subsection{Measurement of Machining Errors}

A 3D optical measuring system based on fringe projection was used to determine the machining errors in the workpieces by analysing the different textural properties to the body [37]. 3-D optical scanning provided point cloud, curves, and meshed data. The obtained data were indexed into the CAD software, which computed and displayed the deviations between the two data sets, as shown in Fig. 8 .

\subsection{Development of B-Rep Based NC Simulation System}

The basic input to the BRep-based NC simulation system is the NC cutter path either in cutter location (CL) format or G/M-code format. After the CL data are interpreted, the swept volume of the cutter is intersected with the blank at every small sampling interval along the tool path and the intersection is considered as the undeformed chip. The geometric simulation of machining calculates the instantaneous contact area between the cutter and work piece at any time. The solid approach-based CWE model and a model to calculate real IMRR, ECD and prediction of milled surface errors were examined. Data related to the milling process was obtained using an in-house application programmer's interface (API) software based on B-rep. After the in-process workpiece geometry was obtained for each $G$ code line, the contact area, and generated surface between the tool and workpiece can be extracted by using the inhouse API as shown in Fig. 9. The IMRR value can be obtained by determining the intersection geometry between cutter swept volume and workpiece during the tooth passing period $\left(t_{p}\right)$ and the volume is divided by tp to compute the average MRR [38]. The chip thickness at any location on the cutting tool is computed as shown in Eq. (1) by dividing the scalar product of the feed $(f)$ with the surface normal vector $\left(N_{s}\right)$ by the number of cutter teeth $\left(n_{t}\right)$, multiplied by the tool rotation values $(\mathrm{N}-\mathrm{rpm})[4]$ :

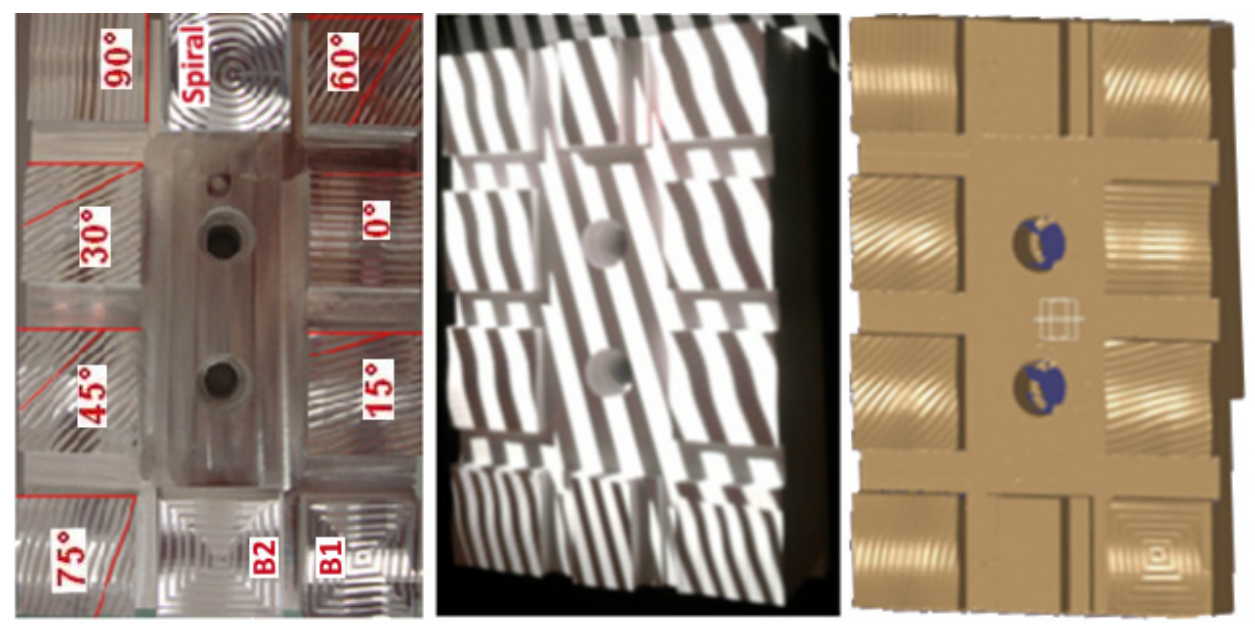

Fig. 8. Real part, fringe projection application and CAD model of machined surfaces 
$M R R=\frac{\int h(\phi, z) d A}{t_{p}}, h(\phi, z)=\frac{f(\phi, z) \cdot N_{s}(\phi, z)}{n_{t} N}$

The chip volume varies according to the surface curvature, feed-rate, and cusp height generated via the previous line of G code. ECD is the main factor used to calculate the required spindle speed and cutting inputs. ECD is explained as the real diameter of the cutter at the axial DoC- line.
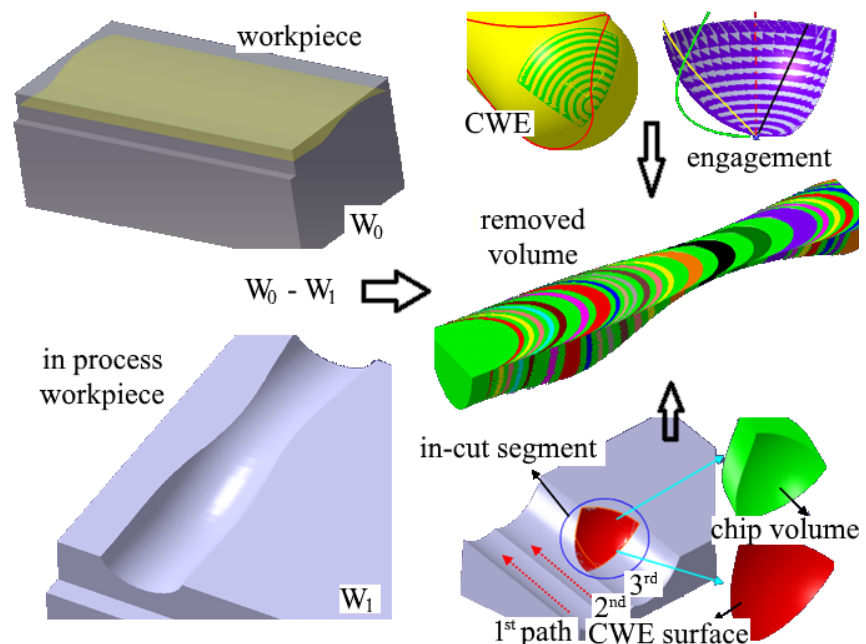

Fig. 9. Calculation of the removed volume, CWE, chip geometry, and workpiece in the developed simulation system
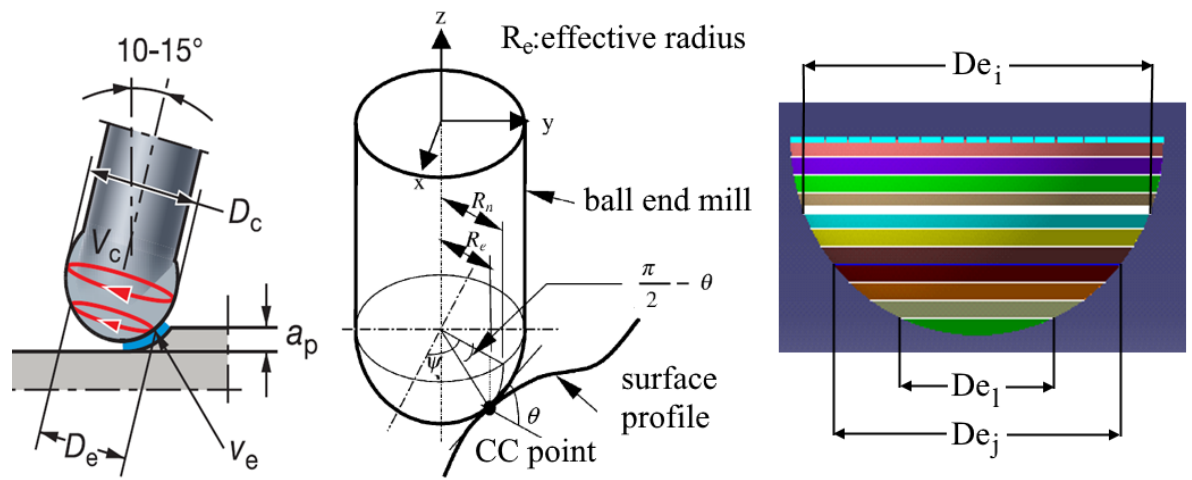

Fig. 10. Relationship between cutter effective radius and surface gradient [4]

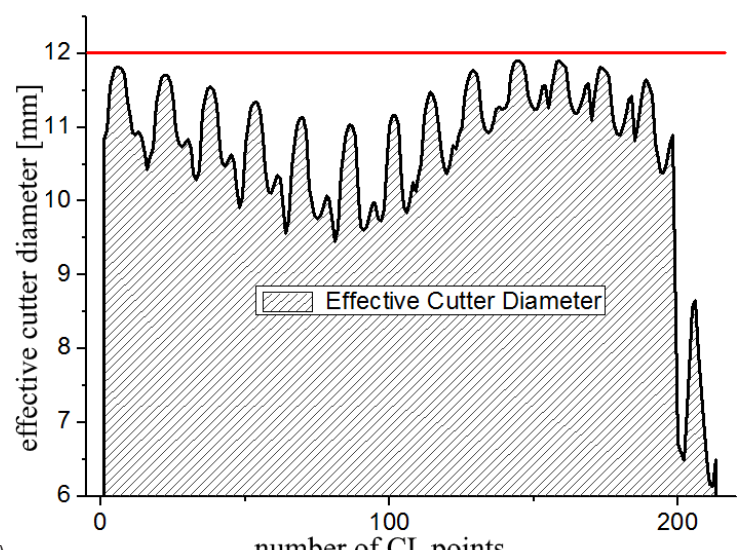

a)

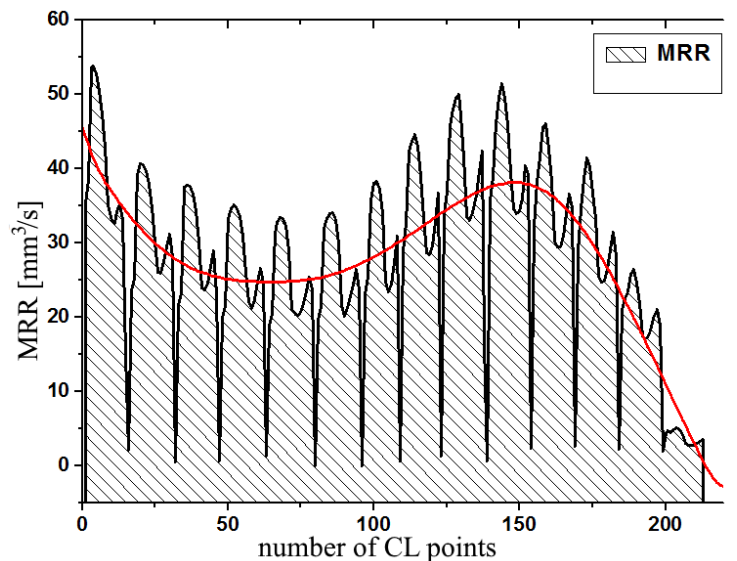

Fig. 11. a) $E C D$ and b) IMRR values for $0^{\circ}$ zig-zag tool path 


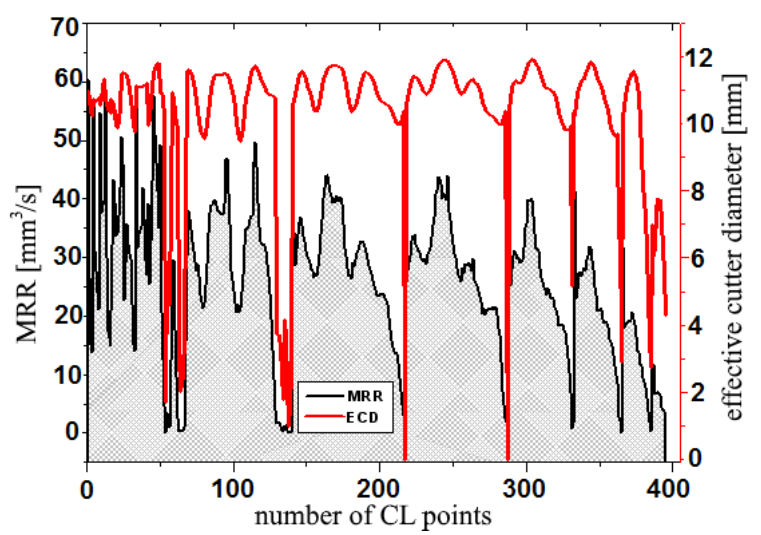

Fig. 12. MRR and ECD values for spiral cutting strategy

The ECD is affected by two factors: cutter radius and axial DoC values. ECD values at each CL point were directly obtained directly from the simulated B-rep interface as shown in Fig. 11. The ECD values during milling without tool inclination are calculated according to Eq. (2) [4] and [39]:

$$
\begin{aligned}
D_{e f f} & =2 \cdot \sqrt{a_{p} \cdot\left(d-a_{p}\right)} . \\
R_{e} & =R_{n} \cos \left(\frac{\pi}{2}-\theta\right) .
\end{aligned}
$$

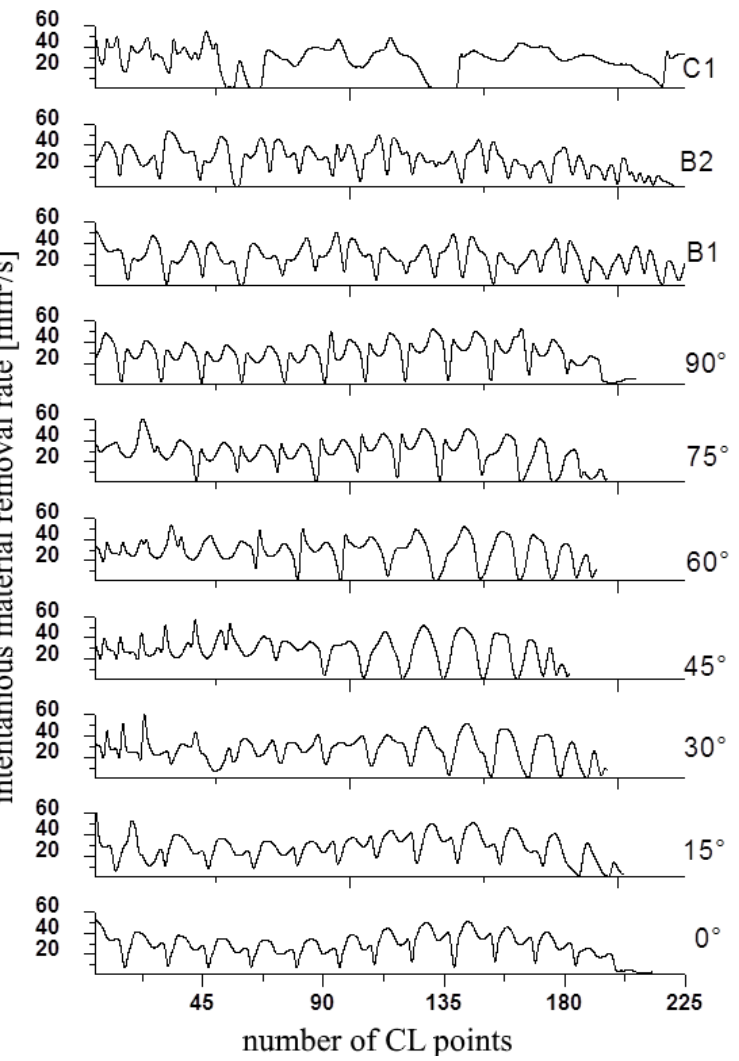

Fig. 13. IMRR values for tool-path strategies
In Eq. (2), the effective radius (the formula for $R_{e}$ is given in Eq. (3), a horizontal distance measured from the rotation centre to the cutter contact point, of the ball-end milling tool varies according to the gradient $\theta$ of the part surface [4]. It is seen that the IMRR and ECD results are very similar, as shown in Figs. 11 and 12. IMRR and ECD values were compared for the various cutting strategies as seen in Figs. 13 and 14. In free-form ball-end milling, depths of cut, ECD, and IMRR values are always changing at every CL point; therefore, different levels of form-errors are left on the sculptured surface. Fig. 11a shows variation of ECD values according to the nominal tool diameter value. ECD, IMRR, and cutting forces values showed similar tendencies.

\section{RESULTS AND DISCUSSION}

\subsection{Analysis of Machining Time}

Tool-path strategy has a considerable effect on the times required to machine curved surfaces. Complex

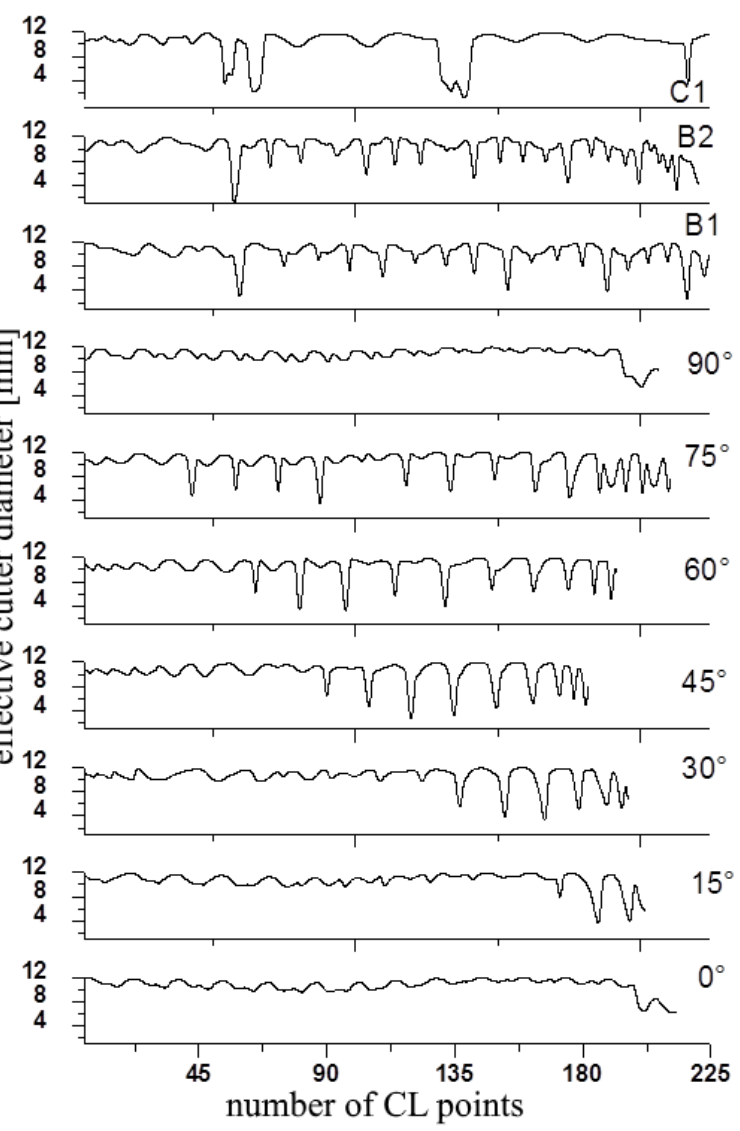

Fig. 14. ECD values for tool-path strategies for nominal cutter diameter $(12 \mathrm{~mm})$ 
part surfaces generally need very long G code lines, resulting in extreme cutting times. Shorter cutting time means greater machining efficiency. Although various cutter paths have different cutting lengths, they remove a similar amount of chip. Removing an almost identical amount of workpiece material in a shorter time reduces the milling time, but has the negative effects of increasing forces, temperature, torque, cutter deflection and form errors. The machining time is measured for each strategy in all experiments as shown in Fig. 15. The $60^{\circ}$ zig-zag strategy shows higher machining time and length cut in comparison to the other strategies. Furthermore, compared with the $60^{\circ}$ zig-zag strategy, machining time could be reduced by employing a profile strategy (B1) at about $61 \%$ and by using a spiral strategy at nearly $63 \%$. The results represent the effect of the path strategies on milling time.

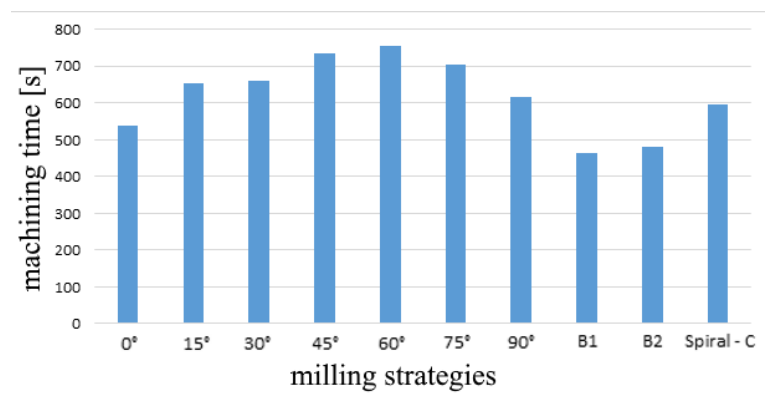

Fig. 15. Machining time for cutter path strategies

\subsection{Analysis of Cutter Deflection, Forces and IMRR}

Milling forces are the main factors governing dimensional accuracy, surface quality, machine vibration, spindle power requirements, energy consumption and cutter life. Proper selection of the cutter path strategy is crucial in achieving the desired machined surfaces.

Therefore, cutting force measurements are carried out to determine the effects of using different tool path strategies in the milling of convex surfaces. Different tool-path strategies are compared in terms of cutting force and tool deflection. The same surface was machined with various tool-paths. The experimental measurements and simulation results agree with each other. This permits engineers to analyse the milling process in advance, and to select the optimum path strategies.

Fig. 16 shows cutting forces and deflections from experiments using the different strategies. It is observed that when milling with a $75^{\circ}$ zig-zag, the highest resultant cutting force and tool deflection values are observed, followed by a $45^{\circ}$ zig-zag and spiral and strategies, respectively. Employing profiling strategy (B1) achieves the lowest cutting force magnitude. Since the comparison between strategies takes place in the same machining conditions, toolchip contact area is one of the reasons for cutting force differences between different strategies.
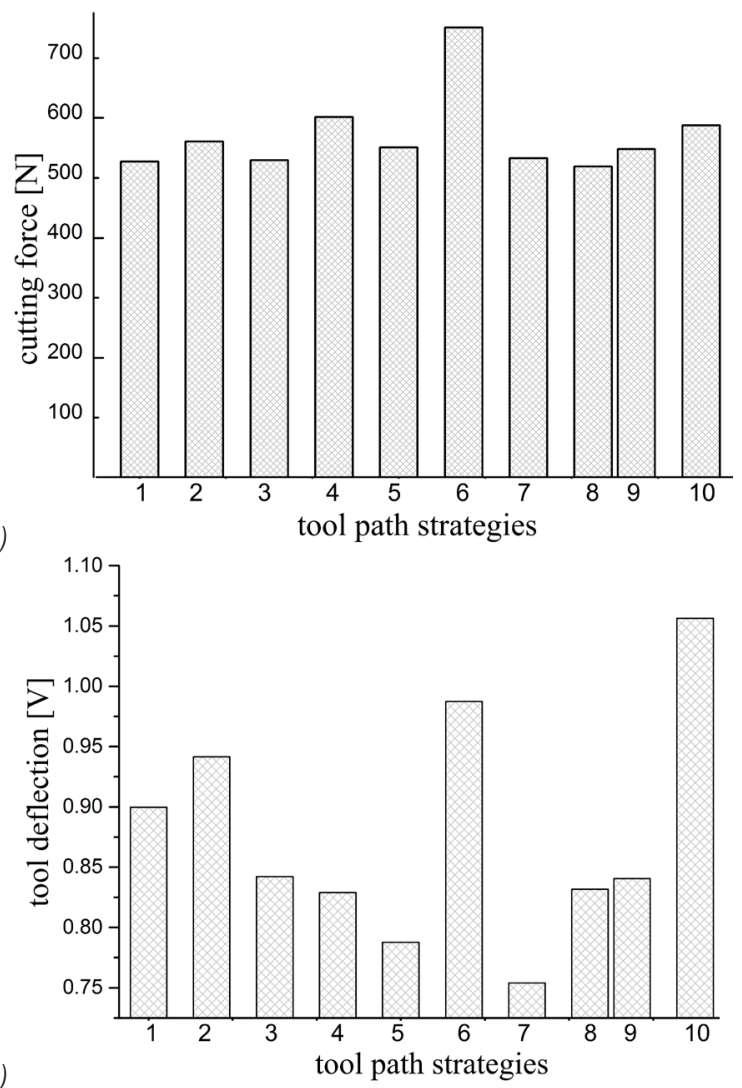

b)

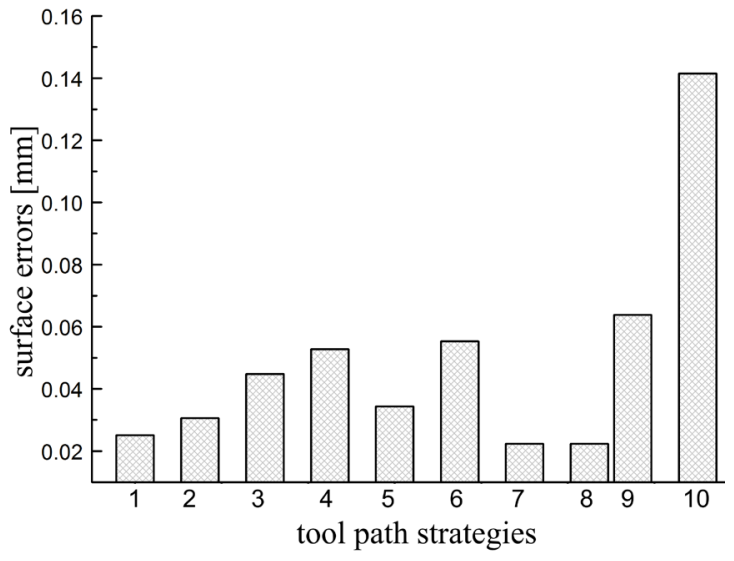

Fig. 16. Cutting forces(a), deflection (b) and max. surface errors values(c) for tool-path strategies

The minimum deflection of the tool occurs for the $90^{\circ}$ zig-zag and profiling strategy (B1). The maximum removed volume values were shown as 
seen in Fig. 17 for per cutter tooth and between two CL points. When the minimum force and minimum cutter deflection are taken into consideration, the $90^{\circ}$ zigzag strategy seems to be more productive. MRR and machining forces are closely related. MRR increases at nearly the same rates as increases in milling forces. The force calculation based on chip volume is very important to obtain accurate IMMR values during the roughing step. Milling forces obtained from experiments and the IMRR values from the B-rep approach were compared with each other. The IMRR and corresponding force profiles are very similar.

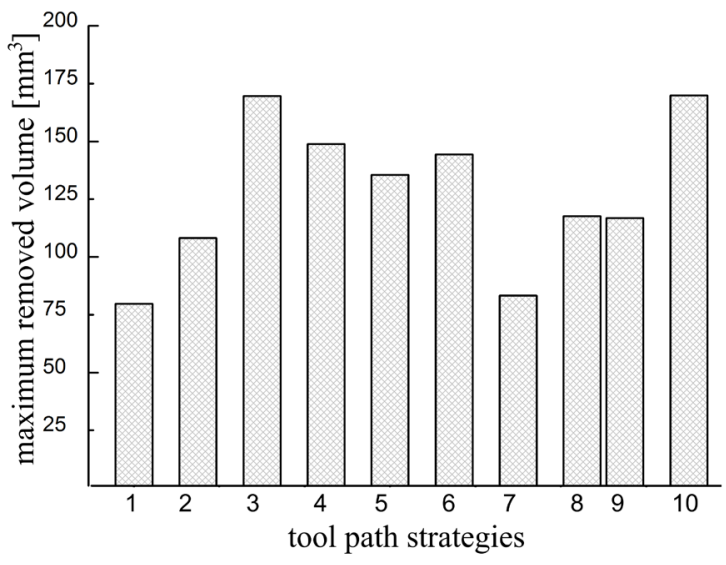

a)

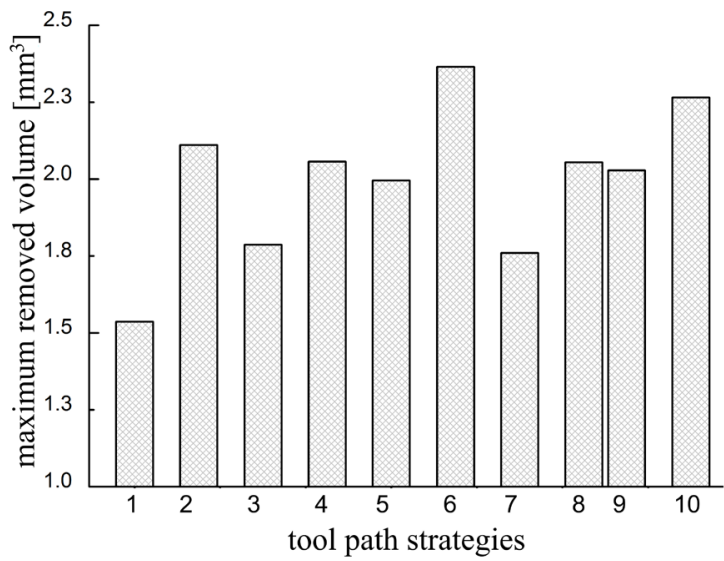

Fig. 17. a) Maximum removed volume values for $C L$ points, and b) cutter per tooth

\subsection{Analysis of Machining Errors}

Errors in milled surfaces result from different factors, such as tool wear, thermal distortion, deflection of the machine tool and cutter, lubrication system, etc. Cutter deflection is the most critical of these parameters for surface form error. The influence of cutter strategies on surface form error was researched empirically. The surface dimensional error depends on the value and direction of the tool deflection. Cantilever beam models were published in the literature. Assuming that the cutter behaves as a cantilever beam, Eq. (4) can be used to compute the resulting deflection [4]:

$$
\delta=\left(\frac{64 F}{3 \pi E}\right)\left(\frac{L^{3}}{D^{4}}\right) .
$$

Some studies within the literature [40] and [41] examined milling errors caused by cutter deflection when machining a sculptured part using a ballend milling tool. Wei et al. [41] examined a flexible model for estimating the form error in three-axis ballend milling of the sculptured surface. In their work, the deflection-dependent cutting-edge engagement was determined by using an iterative procedure, and the form error was obtained from the balanced tool deflection and associated surface inclination angle. In these studies, tool deflection values were obtained using enhanced analytical force models. In this study, surface error results derived from the CAD model and NC simulation system. Tool-path lines, simulation output, real machined surface, and comparison of modelled and real machined surface are presented in Figs. 18 and 19 for the spiral and $0^{\circ}$ zig-zag machining strategy, respectively. Firstly, the original CAD model created in the CATIA environment and the CAD data for the machined surface obtained via fringe projection were converted to the same coordinate system.
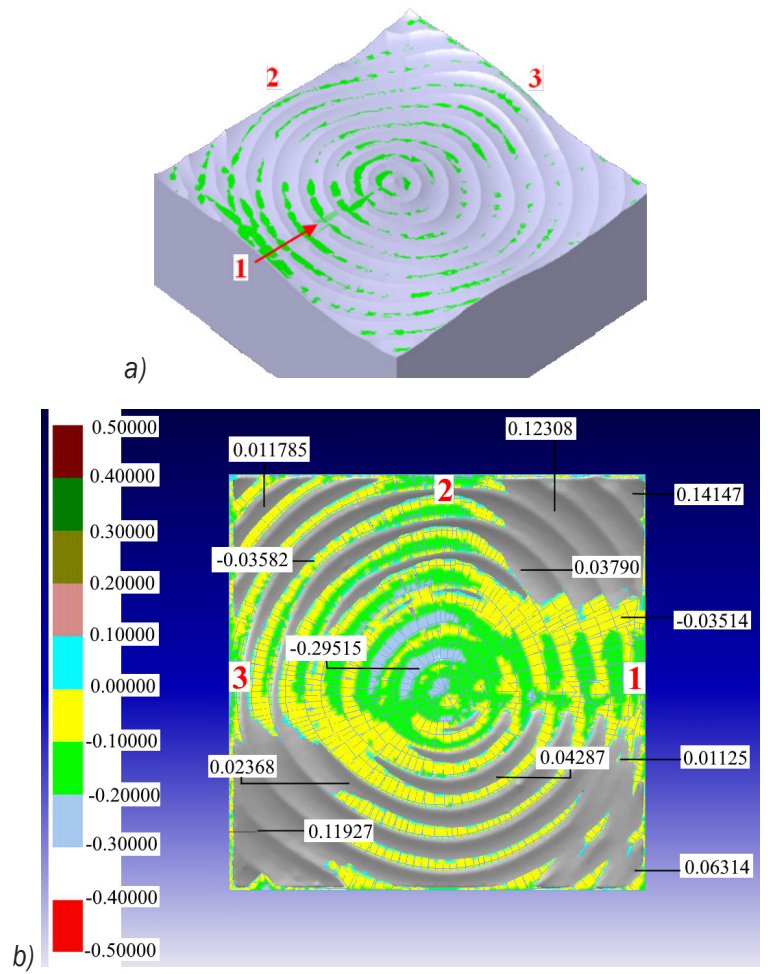

Fig. 18. Machining surface errors for spiral strategy 
Then, the differences between the two CAD models were analysed. In addition, CAD data from B-rep simulation results and the desired target surface are compared with each other. The proposed simulation/analysis approach gives very good results in determining the location of manufacturing form errors. Cutting force values/machining errors and related cutter deflection/machining errors are shown in Fig 16. It is seen that the experimental measurements and simulation results agree with each other for path strategies. Deflection, force, and machining error values showed similar tendencies. Maximum surface errors value occurs in the spiral milling strategy as shown in Table 4.

Table 4. Maximal surface error values for path strategies

\begin{tabular}{lcc}
\hline Tool Path Strategies & & Max. Errors $[\mu \mathrm{m}]$ \\
\hline & $0^{\circ}$ & 25.1 \\
\cline { 2 - 3 } Zig-Zag & $15^{\circ}$ & 30.58 \\
\cline { 2 - 3 } & $30^{\circ}$ & 44.76 \\
\cline { 2 - 3 } & $45^{\circ}$ & 52.77 \\
\cline { 2 - 3 } & $60^{\circ}$ & 34.32 \\
\cline { 2 - 3 } & $75^{\circ}$ & 55.31 \\
\hline \multirow{2}{*}{ Concentric } & $90^{\circ}$ & 22.38 \\
\hline Spiral & on Part surface- B1 & 22.38 \\
\cline { 2 - 3 } & on Plane- B2 & 63.87 \\
\hline
\end{tabular}
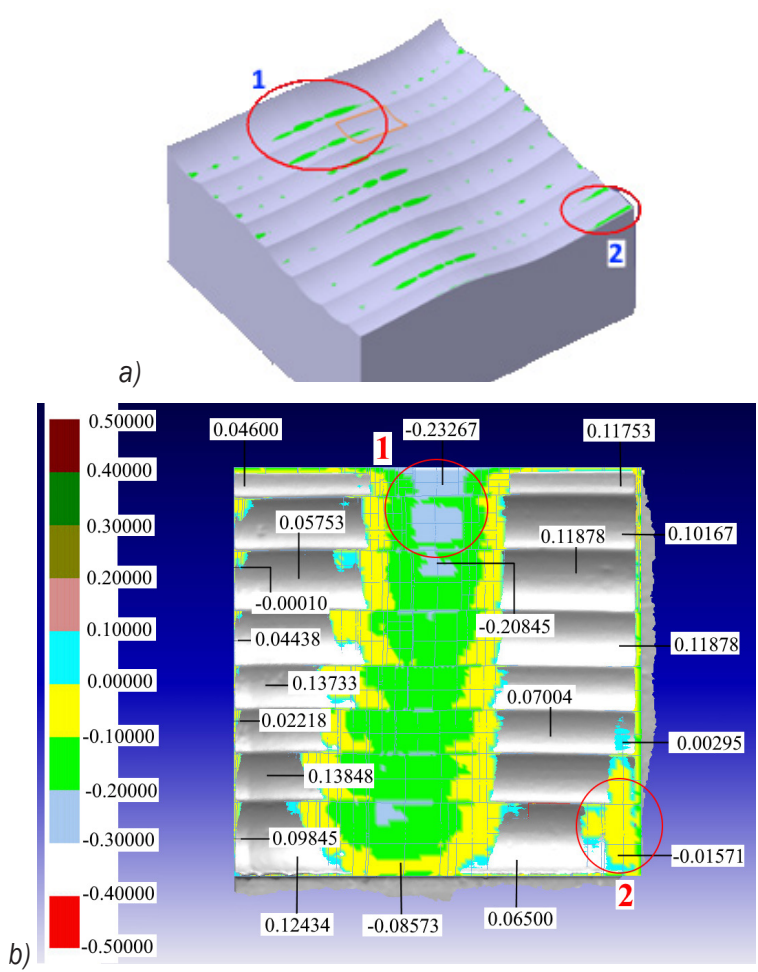

Fig. 19. Surface errors for $0^{\circ}$ zig-zag milling strategy
For this surface geometry, the $90^{\circ}$ zig-zag toolpath gives better results in terms of surface error and tool deflection. Examined in detail, the highest form error values and cutter deflection are observed in the spiral and $75^{\circ}$ zig-zag machining strategies. Deflection values are similar to the trends observed in the milling surface form errors. When the cutting strategies were compared, the cutter-work piece contact area, MRR, and ECD parameters were found to be excessive and subject to sudden changes. Therefore, application of these tool-path strategies results in the highest deflection, force, and form error. The results show that the minimum cutting force, machining errors and cutter deflection occur for the $0^{\circ}$ and $90^{\circ}$ zig-zag machining strategies.

\section{CONCLUSIONS}

The aim of this paper is to examine the effect of tool path strategies on cutting forces, tool deflection, real IMRR values, CWE, surface form errors and cycle times when milling a complex free-form surface. A B-rep solid modeling-based simulation and optimization system was developed and integrated with commercial CAD/CAM software for 3-axis ballend milling. The $60^{\circ}$ zig-zag strategy shows higher machining time and length cut in comparison to the other strategies. Furthermore, compared to the $60^{\circ}$ zig-zag strategy, machining time could be reduced by employing profile strategy (B1) at about $61 \%$ and by using the spiral strategy at nearly $63 \%$. Cutting forces and deflection values were obtained from experiments using the different strategies. It is observed that when milling with $75^{\circ}$ zig-zag, the highest resultant cutting force and tool deflection values are observed, followed by $45^{\circ}$ zig-zag and spiral and strategies, respectively. Employing profiling strategy (B1) achieves the lowest cutting force magnitude. Since the comparison between strategies takes place in the same machining conditions, the tool-chip contact area is one of the reasons for cutting force variations between different strategies. When the force and cutter deflection are taken into consideration, the $90^{\circ}$ zig-zag strategy seems to be more productive.

MRR and machining forces are closely connected parameters. MRR increases at nearly the same rates are milling forces, IMRR, ECD and corresponding force profiles were found to be very similar for different strategies. Cutting force values/machining errors and the relationship between cutter deflection/ machining errors were shown in Fig. 16. Deflection, force and machining errors showed similar variations. The in-house simulation system gave good results 
in determining the location of manufacturing form errors, as seen in Figs. 18 and 19. As results, the maximum surface error was obtained from the profile tool-path and $45^{\circ}$ zig-zag strategy, and there are proportional relationships between cutting force, deflection and form errors. It was observed that the profiles of deflection, IMRR values, cutting forces, machining errors, and ECD values match very well for cutting strategies. The results permit machinists or technicians to better evaluate the milling process for the selection of an efficient tool-path strategy.

\section{REFERENCES}

[1] Marshall, S., Griffiths, J.G. (1994). A survey of cutter path construction techniques for milling machines. International Journal of Production Research, vol. 32, no. 12, p. 28612877, Dol:10.1080/00207549408957105.

[2] Dragomatz, D., Mann, S. (1997). A classified bibliography of literature on NC milling path generation. Computer-Aided Design, vol. 29, no. 3, p. 239-247, D0l:10.1016/S00104485(96)00060-7.

[3] Gologlu, C., Sakarya, N. (2008). The effects of cutter path strategies on surface roughness of pocket milling of 1.2738 steel based on Taguchi method. Journal of Materials Processing Technology, vol. 206, no. 1-3, p. 7-15, D0I:10.1016/J.jmatprotec.2007.11.300.

[4] Kurt, M., Bagci, E. (2011). Feedrate optimisation/scheduling on sculptured surface machining: a comprehensive review, applications and future directions. The International Journal of Advanced Manufacturing Technology, vol. 55, no. 9-12, p. 1037-1067, Dol:10.1007/s00170-010-3131-3.

[5] Lasemi, A., Xue, D., Gu, P. (2010). Recent development in CNC machining of freeform surfaces: A state-of-the-art review. Computer-Aided Design, vol. 42, no. 7, p. 641-654, D0I:10.1016/j.cad.2010.04.002.

[6] Chen, Y., Gao, J.. Deng, HG., Zheng, D., Chen, X., Kelly, R. (2013). Spatial statistical analysis and compensation of machining errors for complex surfaces. Precision Engineering, vol. 37, no. 1, p. 203-212, D0l:10.1016/j. precisioneng.2012.08.003.

[7] Habibi, M., Arezoo, B., Nojedeh, M.V. (2011). Tool deflection and geometrical error compensation by tool path modification. International Journal of Machine Tools and Manufacture, vol. 51, no. 6, p. 439-449, D0l:10.1016/j.jjmachtools.2011.01.009.

[8] Desai, K.A., Rao, P.V.M. (2008). Effect of direction of parameterization on cutting forces and surface error in machining curved geometries. International Journal of Machine Tools and Manufacture, vol. 48, no. 2, p. 249-259, DOI:10.1016/j.jjmachtools.2007.08.007.

[9] Albertí, M., Ciurana, J., Rodriguez, C.A. (2007). Experimental analysis of dimensional error vs. cycle time in high speed milling of aluminum alloy. International Journal of Machine Tools and Manufacture, vol. 47, no. 2, p. 236-246, DOI:10.1016/j.jjmachtools.2006.04.009.

[10] Erdim, H., Lazoglu, I., Kaymakci, M. (2007). Free-form surface machining and comparing feedrate scheduling strategies.
Machining Science and Technology, vol. 11, no. 1, p. 117-133, DOI:10.1080/10910340601172206.

[11] Kaymakci, M., Lazoglu, I. (2008). Tool path selection strategies for complex sculptured surface machining. Machining Science and Technology, vol. 12, no. 1, p. 119-132, DOI:10.1080/10910340801913979.

[12] Brooks, Z., Nath, C., Kurfess, T.R. (2016). Investigating surface metrology of curved wall surface during milling of SS304 with different tool path strategies. The International Journal of Advanced Manufacturing Technology, vol. 86, no. 5-8, p. 1963-1972, Dol:10.1007/s00170-015-8323-4.

[13] Gok, A., Gologlu, C., Demirci, H.I. (2013). Cutting parameter and tool path style effects on cutting force and tool deflection in machining of convex and concave inclined surfaces. The International Journal of Advanced Manufacturing Technology, vol. 69 , no. 5-8, p. 1063-1078, D0l:10.1007/s00170-0135075-x.

[14] Shajari, S., Sadeghi, M.H., Hassanpour, H., Jabbaripour, B. (2012). Influence of machining strategies on surface roughness in ball end milling of inclined surfaces. Advanced Materials Research, vols. 488-489, p. 836-840, D0I:10.4028/ www.scientific.net/AMR.488-489.836.

[15] Vila, C., Abellán-Nebot, J.V., Siller-Carrillo, H.R. (2015). Study of different cutting strategies for sustainable machining of hardened steels. Procedia Engineering, vol. 132, p. 11201127, D0I:10.1016/j.proeng.2015.12.604.

[16] Shajari, S., Sadeghi, M.H., Hassanpour, H. (2014). The influence of tool path strategies on cutting force and surface texture during ball end milling of low curvature convex surfaces. The Scientific World Journal, p. 1-14, DOl:10.1155/2014/374526.

[17] Ižol, P., Vrabel, M., Maňková, I. (2016). Comparison of milling strategies when machining freeform surfaces. Materials Science Forum, vol. 862, p. 18-25, D0l:10.4028/www. scientific.net/MSF.862.18.

[18] Matras, A., Kowalczyk, R. (2014). Analysis of machining accuracy during free form surface milling simulation for different milling strategies. Proceedings of the SPIE, vol. 9290, p. 1-7, DOl:10.1117/12.2075081.

[19] Hassanpour, H., Shajari, S., Rasti, A., Sadeghi, M.H. (2015). Investigation of milling strategies effect on microhardness of a typical curved surface. Modares Mechanical Engineering, vol. 15, no. 2, p. 34-40.

[20] Pahole, I., Studenčnik, D., Gotlih, K., Ficko, M., Balič, J. (2011). Influence of the milling strategy on the durability of forging tools. Strojniški vestnik - Journal of Mechanical Engineering, vol. 57, no. 12, p. 898-903, D0l:10.5545/sv-jme.2010.078.

[21] Schützer, K., Abele, E., Stroh, C., Gyldenfeldt, C. (2007). Using advanced CAM-systems for optimized HSC-machining of complex free form surfaces. Journal of the Brazilian Society of Mechanical Sciences and Engineering, vol. 29, no. 3, p. 313316, DOI:10.1590/S1678-58782007000300012.

[22] Lazoglu, I., Manav, C., Murtezaoglu, Y. (2009). Tool path optimization for free form surface machining. CIRP Annals - Manufacturing Technology, vol. 58, no. 1, p. 101-104, DOI:10.1016/j.cirp.2009.03.054.

[23] Zhang, X.F., Xie, J., Xie, H.F. (2012). Experimental investigation on various tool path strategies influencing surface quality and 
form accuracy of CNC milled complex freeform surface. The International Journal of Advanced Manufacturing Technology, vol. 59, no. 5-8, p. 647-654, Dol:10.1007/s00170-011-3515-z.

[24] Wei, Z.C., Wang, M.J., Tang, W.C. (2013). Form error compensation in ball-end milling of sculptured surface with z-level contouring tool path. The International Journal of Advanced Manufacturing Technology, vol. 67, no. 9-12, p. 2853-2861, DOl:10.1007/s00170-012-4698-7.

[25] Cao, Q.Y., Zhao, J., Zhu, L. (2016). The effect of curvature radius of sculptured surface on finish milling tool path selection. The International Journal of Advanced Manufacturing Technology, vol. 89, no. 9-12, p. 3349-3357, D0l:10.1007/s00170-0169273-1.

[26] Tan, L., Yao, C., Ren, J., Zhang, D. (2017). Effect of cutter path orientations on cutting forces, tool wear, and surface integrity when ball end milling TC17. The International Journal of Advanced Manufacturing Technology, vol. 88, no. 9-12, p. 2589-2602, DOI:10.1007/s00170-016-8948-y.

[27] Uhlmann, E., Abackerli, A.J., Schützer, K., Lepikson, H.A., Helleno, A.L. Papa, M.C.O., del Conte, E.G., Mewis, J. (2014). Simulation and analysis of error impact on freeform surface milling. The International Journal of Advanced Manufacturing Technology, vol. 70, no. 1-4, p. 607-620, D0l:10.1007/ s00170-013-5280-7.

[28] Scandiffio, I., Diniz, A.E., de Souza, A.F. (2016). Evaluating surface roughness, tool life, and machining force when milling free-form shapes on hardened AISI D6 steel. The International Journal of Advanced Manufacturing Technology, vol. 82, no. 9-12, p. 2075-2086, Dol:10.1007/s00170-015-7525-0.

[29] Tunc, L., Stoddart, D. (2017). Tool path pattern and feel direction selection in robotic milling for increased chatter-free material removal rate. The International Journal of Advanced Manufacturing Technology, vol. 89, no. 9-12, p. 2907-2918, DOI:10.1007/s00170-016-9896-2.

[30] Scandiffio, I., Diniz, A.E., de Souza, A.F. (2017). The influence of tool-surface contact on tool life and surface roughness when milling free-form geometries in hardened steel. The International Journal of Advanced Manufacturing Technology, vol. 92, no. 1-4, p. 615-626, D0l:10.1007/s00170-017-0093-8.

[31] Cao, Q., Xue, D., Zhao, J., Li, Y. (2011). A cutting force model considering influence of radius of curvature for sculptured surface machining. The International Journal of Advanced Manufacturing Technology, vol. 54, no. 5-8. p. 821-835, DOI:10.1007/s00170-010-2980-0.
[32] Miao, Y., Song, X., Jin, T., Shan, Y. (2016). Improving the efficiency of solid-based NC simulation by using spatial decomposition methods. The International Journal of Advanced Manufacturing Technology, vol. 87, no. 1-4, p. 421435, D0l:10.1007/s00170-016-8450-6.

[33] Li, J.G., Ding, J., Gao, D. (2010). Quadtree-array-based workpiece geometric representation on three-axis milling process simulation. The International Journal of Advanced Manufacturing Technology, vol. 50, no. 5, p. 677-687, DOI:10.1007/s00170-010-2530-9.

[34] Aras, E., Albedah, A. (2014). Extracting cutter/workpiece engagements in five-axis milling using solid modeler. The International Journal of Advanced Manufacturing Technology, vol. 73, no. 9-12. p. 1351-1362, D0l:10.1007/s00170-0145853-0.

[35] Lee, S.W., Nestler, A. (2012). Virtual workpiece: workpiece representation for material removal process. The International Journal of Advanced Manufacturing Technology, vol. 58, no. 5-8, p. 443-463, D0l:10.1007/s00170-011-3431-2.

[36] Boz, Y., Erdim, H., Lazoglu, I. (2015). A comparison of solid model and three-orthogonal dexelfield methods for cutterworkpiece engagement calculations in three- and fiveaxis virtual milling. The International Journal of Advanced Manufacturing Technology, vol. 81, no. 5-8, p. 811-823, Dol:10.1007/s00170-015-7251-7.

[37] Defne Mühendislik. Design, from http://www. defnemuhendislik.com/en.html, accessed on 2015-06-26

[38] Nehez, K. (2002). Computer Simulation of the Milling Optimization. University of Miskolc, Miskolc. (in Hungarian)

[39] Sadílek, M., Čep, R., Budak, I., Soković, M. (2011). Aspects of using tool axis inclination angle. Strojniški vestnik - Journal of Mechanical Engineering, vol. 57, no. 9, p. 681-688, DOI:10.5545/sv-jme.2010.205.

[40] Lim, E.M., Menq, C.H. (1997). Integrated planning for precision machining of complex surfaces. Part 1: Cutting-path and feed rate optimization. International Journal of Machine Tools and Manufacture, vol. 37, no. 1, p. 61-75, D0l:10.1016/08906955(95)00109-3.

[41] Wei, Z.C., Wang, M.J., Cai, Y.J., Zhu, J.N., Wang, L. (2013). Form error estimation in ball-end milling of sculptured surface with z-level contouring tool path. The International Journal of Advanced Manufacturing Technology, vol. 65, no. 1-4, p. 363369, D0I:10.1007/s00170-012-4175-3. 